\title{
How Yoopers See the Future of their Communities: Why Residents Leave or Stay in Michigan's Upper Peninsula
}

\author{
JESSICA D. ULR I C H
}

$\Lambda$ menity-rich rural communities throughout the United States are generally growing in population. By contrast, rural communities dependent on declining natural resource industries have been decreasing in population. ${ }^{1}$ To investigate how rural Americans view socioeconomic and environmental changes affecting their lives and communities, researchers at the Carsey Institute are conducting surveys in rural communities throughout the United States as part of the Community and Environment in Rural America (CERA) study. Drawing on the survey conducted in the Upper Peninsula (UP) of Michigan, this report explores how Yoopers view their own future and that of their community. ${ }^{2}$

Most respondents (88 percent) said that they plan to remain in the UP for at least the next five years. The general quality of life is the most frequently cited reason. Nonetheless, despite this aspiration to stay, the eastern UP is losing population due to out-migration. Although unemployment rates in the UP fluctuate significantly by season, they are generally higher than both the state of Michigan and the entire United States. Lack of employment opportunities and rising energy costs were the problems most frequently cited both by residents planning to stay in the region for the next five years (stayers) and those planning to leave (leavers). ${ }^{3}$ These findings suggest the need for jobs and energy solutions to counter the trend toward out-migration.

Although less than half (48 percent) of UP residents think that the local government can effectively solve important local problems, a majority believe that community members can work together to address local problems, are willing to help one another, and generally trust one another and get along. Whether community individuals and groups can be harnessed to play an important role in shaping the UP's future development remains to be seen over the next few years, as the region wrestles with strategies to achieve economic revitalization.

\section{Key Findings}

In August 2008, researchers from the Carsey Institute surveyed 1,008 residents from five counties in the Upper Peninsula (UP) of Michigan about socioeconomic and environmental issues. Key findings include the following:

- Eighty-eight percent of Yoopers plan to stay in the UP for the next five years. Those who plan to leave are typically younger and unmarried.

- General quality of life ranks highest among reasons for staying in the UP. Natural beauty, proximity to family, and outdoor or recreational activities were also important for those planning to stay.

- Employment opportunities were more important for Yoopers planning to leave than for those planning to stay.

- Yoopers were least likely to cite educational or housing opportunities as important reasons for staying in the UP.

- A high percentage of residents, irrespective of whether they plan to stay or leave, cited high energy costs and lack of job opportunities as important problems facing their communities.

- Forty-eight percent of the people planning to stay in the UP for the next five years think that the local government can effectively solve important problems.

- The majority of Yoopers believe that community members can work together to address local problems, are willing to help one another, and generally trust one another and get along. 


\section{Changes in Rural America}

In order to better understand changes occurring throughout rural America, in 2007, researchers at the Carsey Institute surveyed almost 8,000 randomly selected residents in nineteen purposefully chosen counties throughout rural America. ${ }^{4}$ Through these and subsequent surveys, researchers gained insights about the variety of trends and patterns of change occurring throughout rural America. This information helps to provide rural communities with accurate and relevant information about residents' opinions, attitudes, and experiences regarding social, economic, and environmental concerns. We hope that CERA information will assist decision makers, community organizations, and policy specialists planning sustainable futures in their respective communities.

In August 2008, a second phase of the study was conducted in five counties in the eastern UP of Michigan: Alger, Luce, Mackinac, Schoolcraft, and Chippewa. One thousand and eight randomly selected respondents participated in a telephone survey that asked them approximately 100 questions about general demographic information and their opinions on a variety of socioeconomic and environmental issues. This brief presents initial findings from the survey about whether and why residents plan to leave or stay in the UP, problems residents perceive there, residents' perceptions about the ability of their communities and local government to solve these problems, and possible solutions to the problems the UP is facing.

\section{Changes in the UP}

The UP is one-third of Michigan's land area. Yet it is home to only 4 percent of the state's population. ${ }^{5}$ In addition to the already sparse population, four out of the five counties surveyed in the eastern UP are declining in population because of domestic out-migration (more migration from the UP to other places in the United States than vice versa) and natural decrease (more deaths than births). Alger, Luce, Mackinac, and Schoolcraft counties all saw their populations decrease from 2000 to 2009, with Mackinac County having the greatest loss of 11.3 percent of its population. The only county with population growth was Chippewa County, with an increase of only .5 percent. This was primarily because of natural increase (more births than deaths) rather than in-migration. ${ }^{6}$ Rather than focus on the effects of natural increase or decrease, this brief considers the reasons for net out-migration-why more people are choosing to move from the UP than to the UP. Although CERA data only accounts for Yoopers' reasons behind leaving or staying in the UP, it can also help shed light on why few people are moving to the UP.
Changes in the UP's population reflect changes in its economic base. Although to a lesser degree in the eastern part, the UP as a whole depended on mining and forest-based industries throughout the nineteenth and twentieth centuries to provide much of its employment and income. Like other regions that depend upon natural resources, this makes the UP economy vulnerable to cycles of boom and bust. ${ }^{7}$ The gradual decrease throughout the twentieth century in the number of jobs and revenue associated with mining and forest-based industries has left UP residents in a long-term bust and has made residents of the eastern UP increasingly dependent upon the government and service industry to provide employment. $^{8}$

Unemployment rates near the time of the survey (July 2008) ranged from 4.6 percent in Mackinac County to 10.2 percent in Schoolcraft County, giving the region an average unemployment rate of 8.4 percent. ${ }^{9}$ This rate was above average for the United States at the time (6 percent), but it was slightly lower than the average for the entire state of Michigan (9.1 percent), which has been plagued by high unemployment rates in recent years. More importantly, this rate does not take into account seasonal variation. Because employment in the UP is highly seasonal, employment rates in the winter, or "off-season" range from 11.6 in Luce County to over 27.6 percent in Mackinac County, giving the UP an average unemployment rate of 16.7 percent (January 2009). This off-season rate is much higher than the state of Michigan (12.5 percent) and the United States as a whole (8.5 percent).

On top of high unemployment rates, the UP also currently ranks high on measures of poverty. If the UP were to be considered its own state, it would rank forty-eighth in per capita income. ${ }^{10}$ Poverty makes it more difficult for Yoopers either to stay or leave. In other words, residents struggle to provide basic necessities for themselves and their families, and at the same time, because of a lack of financial resources, they are unable to move someplace else where more employment or educational opportunities are available.

Four broad types of rural communities have been identified in CERA research: amenity rich, declining resource dependent, chronic poverty, and mixed amenity rich/declining resource dependent. ${ }^{11}$ CERA researchers consider the five counties in the eastern UP to be both declining resource dependent and amenity rich. Although the decline in its population and economic base is an important part of the character of the UP, so are the abundant and accessible natural resources. Amenity/decline regions like the UP do not have as many attractions to bring in new population and jobs unlike solely amenity rich regions, such as places in the Rocky Mountains. On a positive note, the UP has not suffered from long-term scarcity, as is the case in chronic poverty regions in the "Black Belt," Delta, or Appalachia. This is because of the periods of growth in the UP's economy 
as a result of its natural resources. Although the UP does boast a number of natural amenities that are attractive to both residents and tourists, these have not been sufficient to drive recent, significant economic growth. In amenity/ decline regions like the UP, there are few stable, high-paying jobs to keep residents there and even fewer jobs to attract newcomers. So what does keep residents in place in the five easternmost counties of the UP? Who is likely to continue to stay a Yooper and what is their outlook on the future?

\section{Staying or Leaving}

Census data from 2008 indicates that the population of the eastern UP is generally declining. To understand this decline and trends for the future, the CERA survey asked whether or not survey respondents plan to leave the region within the next five years. CERA data indicates that 88 percent of UP residents surveyed expect to continue living in the area for the next five years, while 12 percent plan to leave. To understand more specifically how the UP may be changing, it is useful to look at how those who plan to stay differ from those who plan to leave.

Although leavers' and stayers' sex, education levels, and familial ties to the region are similar, these two groups differ in other ways. Leavers are significantly more likely than stayers to be young and unmarried. These findings resemble conclusions from other rural areas experiencing population loss. ${ }^{12}$ Whether or not they want to stay, many young, single residents are finding that there are few employment opportunities in their home communities that meet their goals and expectations. ${ }^{13}$ This lack of opportunity forces them to look elsewhere for jobs.

In addition to their own aspirations, rural teenagers are often encouraged by parents or mentors to leave their community for education or jobs. On our survey, four out of five adult respondents said that they would advise a teenager to move away from their community "for opportunities somewhere else." Thus even adults who have chosen to live and work in the UP concur that teenagers could have a better future if they moved elsewhere.

Losing younger generations of educated residents can have significant effects on the economic and social realities of rural communities. Without a younger generation to work in needed professions (health care in particular) or contribute to local economies, the aging population risk losing needed financial, social, and even medical support. Additionally, a loss in tax revenue means that the local government may struggle to maintain basic public services, such as schools, hospitals, and roads.

\section{Reasons for Staying in the UP}

It's an edgy place. I mean, in the sense that it still hangs on out there like a rawhide flap of the old frontier, outposted from the swirl of mainstream America. The U.P. is a hard place.

A person has to want to hurt a lot to live there. -John G. Mitchell, Audubon Magazine, November 1981

If the UP "is a hard place," why, then, do some people choose to stay in the region? How do their reasons differ from those who plan to leave? Answers could tell us something about the future directions of change or stability in the region. When asked a general question about whether they think their community will be a worse place, about the same, or a better place in ten years, a majority of both stayers and leavers said that they believe their community will be "about the same." Why do residents' have such blasé outlooks for the future of their communities? Perhaps such attitudes about the future of the UP reflect Yoopers' desire for their community not to change. Figure 1 outlines the differences between stayers and leavers in the reasons for their plans over the next five years.

Both stayers and leavers most frequently cited "general quality of life" as an important thing to consider when deciding whether or not they want to stay in the area (see Figure 1). Nearly three out of four, or 72 percent, of stayers and 63 percent of leavers say that the quality of life provided by living in the region is very important to them. General quality of life includes a wide variety of experiences particular to each respondent. That it ranks the highest for both stayers and leavers indicates that the UP may provide a generally attractive lifestyle for its residents. Just as most Yoopers see their community as being "about the same" in ten years, they may also appreciate the relative stability that living in a rural setting as opposed to an urban setting provides.

The natural beauty of the area, the availability of outdoor or other recreational activities, and proximity to family were central considerations for both stayers and leavers. Qualities of the UP that relate to the natural environment were ranked high by both groups, indicating that life in the UP is closely linked with nature for many residents regardless if it relates to employment or recreation. In fact, Yoopers are generally known for their fierce love of the outdoors even during the famously harsh winters. Scandinavian heritage and tradition are also widespread in the UP, perhaps providing another reason people are reluctant to leave. ${ }^{14}$

Housing and educational opportunities were cited least frequently by both stayers and leavers. This seems to reflect the limited educational and housing opportunities in the UP, which lacks major universities and metropolitan areas. 
FIGURE 1. DO THE FOLLOWING THINGS SEEM NOT IMPORTANT, SOMEWHAT IMPORTANT, OR VERY IMPORTANT TO YOU WHEN YOU THINK ABOUT WHETHER YOU WILL STAY HERE OR MOVE AWAY IN THE FUTURE?

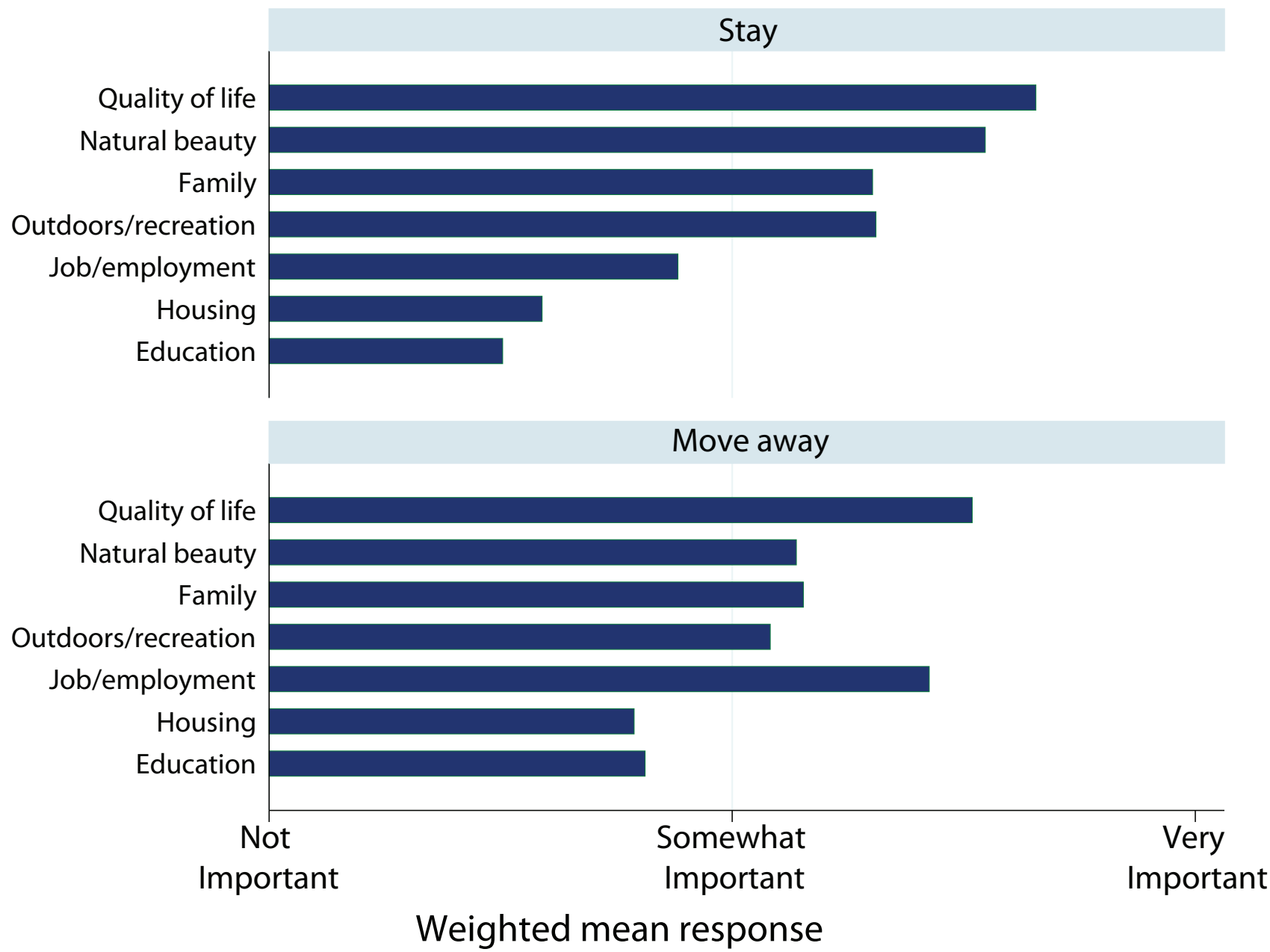

Apart from these general similarities, stayers and leavers showed some differences as well. Stayers were significantly more likely than leavers to cite the natural beauty of the area as very important. About 65 percent of stayers said that the natural beauty of the area was a very important consideration when they think about whether they will stay or leave the area in the future, in contrast to only 38 percent of leavers who think natural beauty is very important. Natural beauty and availability of outdoors or other recreational opportunities even trump employment opportunities for those who plan to stay. This again reinforces how important the natural environment is to Yoopers. Many are willing to stay despite dwindling employment opportunities because they believe that the natural beauty of the area ( 65 percent) and being close to family (54 percent) are very important.
Leavers were significantly more likely than stayers to cite employment and educational opportunities as very important. Among those planning to leave, employment opportunities were second only to quality of life. That educational opportunities are more important to those planning to leave suggests that leavers may perceive the educational opportunities in the UP to be insufficient in meeting their needs. These findings suggest that although general quality of life is important to leavers, they feel it necessary to move in order to pursue job and educational opportunities elsewhere. That particularly applies to young, single Yoopers. If residents are unable to provide for their basic necessities or educational aspirations, other considerations may matter less. 
FIGURE 2. DO YOU CONSIDER THE FOLLOWING TO BE IMPORTANT PROBLEMS FACING YOUR COMMUNITY TODAY?

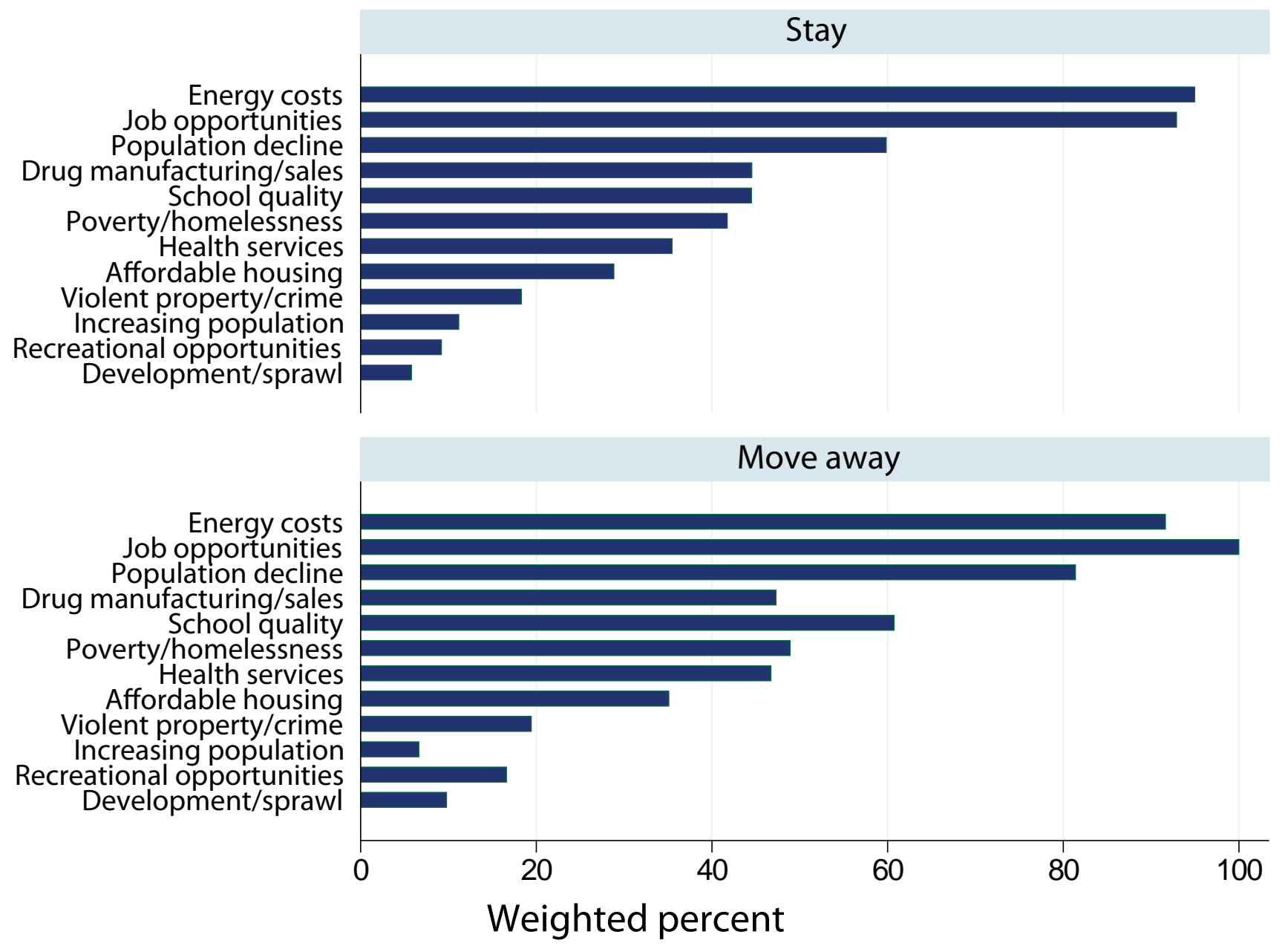

\section{Perceived Problems}

Knowing what problems Yoopers identify in their communities can help shape policies for the future. Previous CERA findings have shown that besides a general concern about employment, most problems vary greatly from place to place. ${ }^{15}$ By further examining the differences between stayers and leavers, we can understand what factors push residents to leave and what factors may pull in new residents. The CERA survey asked a wide variety of questions about the types of community problems residents perceived (see Figure 2).

Figure 2 shows that "rising costs of energy for transportation, home, or business" and "lack of job opportunities" were the most frequently cited community-level problems for Yoopers. In fact, 95 percent of stayers and 92 percent of leavers indicated that rising energy costs were an important problem facing their community. Additionally, 93 percent of stayers and 100 percent of leavers cited lack of employment opportunities as an important problem. The high percentage of both stayers and leavers citing rising energy costs and job opportunities as important problems underlines the centrality of these challenges. A high priority on jobs and energy prices might be found anywhere in the United States these days, but rural America's situation seems particularly acute. In the Place Matters report that analyzed CERA data from nineteen rural communities throughout the United States, researchers found that all of the communities surveyed had high levels of concern about a lack of job opportunities.

Both stayers and leavers also frequently cited "population decline as people move away" as an important problem. Almost 60 percent of stayers cited population loss as a significant issue in the region, while over 81 percent of leavers saw 
it as important. These relatively high percentages indicate that both stayers and leavers are aware of the problems associated with population decline. Despite this awareness, leavers are unable to prevent their own contribution to this problem perhaps because of the lack of employment or educational opportunities in the UP.

Despite the fact that the majority of Yoopers saw job opportunities and population decline as important problems facing the UP, there were significant differences in how stayers and leavers viewed these problems. Those planning to leave considered these problems to be more important than those planning to stay. It makes sense that those who perceive more problems with a community, especially with employment opportunities, may be more likely to leave in the near future. Leavers may also be more concerned with population decline because they are more aware of the likelihood that they, and others, may leave the region to seek opportunities elsewhere.

A substantial number of respondents also considered manufacturing or sales of illegal drugs (45 percent), substandard schools (47 percent), and poverty or homelessness (43 percent) as important problems their communities face (see Figure 2). These are problems facing many rural communities throughout the United States and it is not surprising that UP residents also perceive them as important since they are problems often associated with a lack of employment opportunities.

"Community changing as too many people move in," "toorapid development, growth or sprawl" and "lack of recreational opportunities" were considered important problems by the fewest number of respondents. Only 11 percent of Yoopers were concerned about too many people moving to their community and changing it and only six percent said that growth or sprawl was a problem. That population increase and sprawl/development were not considered important problems further reflects the awareness respondents have about the lack of growth and development in these communities. Only ten percent of Yoopers said that the UP was lacking in recreational opportunities. The lack of concern about recreational opportunities parallels the finding regarding why people choose to remain in the UP-the abundance of natural resources that facilitate recreational opportunities and enhance the general quality of life.

Figure 3. Do YOU AGREE OR DISAGREE WITH THE FOLLOWING STATEMENTS ABOUT YOUR COMMUNITY?
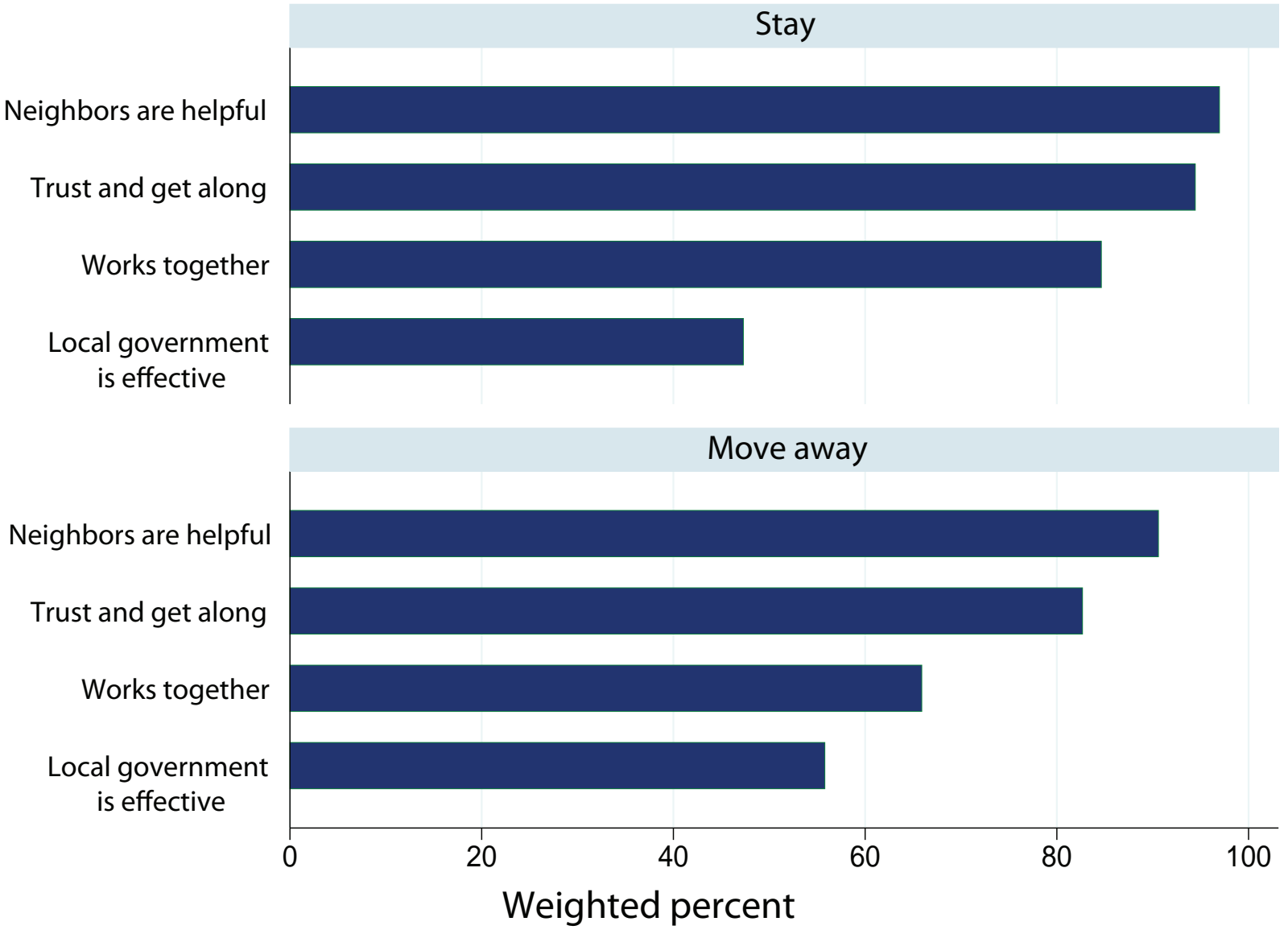


\section{Responding to Change}

What sort of solutions to community problems do Yoopers see as feasible? Using local knowledge about what is and is not working to solve issues may be the most effective way to ameliorate problems and help reverse out-migration and job loss. Figure 3 outlines how residents see civic culture issues and the effectiveness of local government in dealing with problems.

Most strikingly, less than half (48 percent) of Yoopers think that the local government can effectively deal with important problems (see Figure 3). Over 47 percent of stayers and 56 percent of leavers indicated a relative lack of faith in the local government to solve important local problems. On an optimistic note, a high percentage of stayers ( 97 percent) and leavers (91 percent) said that people in their community are willing to help their neighbors. A high percentage of both stayers ( 94 percent) and leavers ( 83 percent) also said that people in their communities generally trust one another and get along. Finally, respondents were also generally optimistic about the ability of their community to work together. Approximately 85 percent of stayers and 66 percent of leavers said that they believed people in the community could be counted on to work together to solve local problems in the future. Past CERA research has found that high levels of trust and social cohesion within communities is the norm throughout much of rural America except in chronically poor regions. ${ }^{16}$

Both stayers and leavers were more skeptical about the ability of the local government to deal with problems than they were about the ability of the community to deal with problems. However, stayers had more faith in the community than leavers. Stayers were significantly more likely than leavers to agree that community members are willing to help their neighbors. Stayers were also significantly more likely to agree that people in the community generally trust one another and get along. When asked "if this community were faced with a local issue such as the pollution of a river or the closure of a school, people here could be counted on to work to address it," stayers were significantly more likely than leavers to agree.

These findings could be indicative of the fact that leavers are not as connected or involved in their community's civic culture. This means they may be more skeptical about the future of their respective communities. Differences in opinion between stayers and leavers could also be a reflection of the fact that leavers are often much younger than stayers and subsequently may be less likely to be involved in and informed about local civic culture. These findings also tell us that with a high level of trust, willingness to help neighbors, and faith that the community will work together, stayers could focus on the community to begin solving important local problems.

\section{The Future of Michigan's UP}

Transitioning amenity/decline regions such as the UP face an uphill struggle against out-migration trends in seeking a more sustainable future. ${ }^{17}$ In the CERA survey, residents have said loud and clear that a lack of jobs, high energy prices, and declining population are important problems that need to be addressed. Unfortunately, since the survey was conducted in August 2008, unemployment rates in the UP have grown even higher. The economic recession that spiked unemployment rates across the United States has also had an affect on the UP. Unemployment rates as of March 2010 range from 16.3 percent in Luce County to over 30 percent in Mackinac County, giving the eastern UP an average rate of approximately 20 percent. ${ }^{18}$ This unemployment rate is higher than the state of Michigan (14.9 percent), which continues to be the highest in the nation. The UP's unemployment rate is also higher than the U.S. rate of 10.2 percent. Given these circumstances, what kinds of economic revitalization efforts are feasible in the UP? How can the UP attract both more jobs and more residents?

\section{Policy and Development Implications}

Although this is not a novel idea for the region, one possible way to create more jobs and revenue and attract new residents is through the tourism industry-as seen in some other rural regions with a high potential for outdoor recreation and a high quality of life. At one time, a region with a high proportion of blue collar middle-class jobs dependent upon natural resources, the UP today is being forced to change how it views and uses its natural resources. Rather than treating them as something to extract and sell, the future of the UP may now rely upon the preservation and maintenance of its natural amenities that could attract new kinds of development. Just as UP residents appreciate the natural beauty and outdoor recreational opportunities of the region, tourists or new residents could appreciate them, allowing Yoopers to benefit from new revenue and jobs.

However, there are limitations to depending on the tourism industry for economic development. First of all, opinions over whether or not to use natural resources for growth are divided in the UP. Although the tourism industry does not always directly use natural resources in the same ways as resource-dependent industries like logging or mining, it can have negative impacts on the natural environment of a place. When Yoopers were asked whether it was more important to use natural resources to create jobs or to conserve natural resources for future generations, 39 percent favor job creation, 40 percent say conservation should be a priority, and 21 percent say that both priorities should be equally considered. Although 
Yoopers are more likely to favor using natural resources for job creation, previous CERA research documented similar divisions between rural Americans on environmental conservation issues. ${ }^{19}$ Across rural America, 29 percent favored job creation, 43 percent favored conserving resources, and 28 percent thought that both priorities should be weighed equally. Secondly, the tourism industry, like mining and logging, is prone to cycles of boom and bust. This means that UP residents should not depend solely on the tourism industry for economic revitalization.

Those arguing for conservation of the UP's natural resources may appreciate a development strategy that is environmentally responsible. For example, a focus on ecotourism, green-traveling, or geotourism may be a more sustainable route for a region known for its natural beauty and amenities. In this way, environmental damage to the local environment can be reduced and the region will be able to benefit from diversifying its economic base.

This brief's findings not only suggest the need for jobs and energy solutions to counter the trend toward outmigration, but it also suggests other ways in which UP policy makers could improve the daily lives of Yoopers and the future of the UP. For example, policy makers should think about ways to improve things such as educational and housing opportunities. Yoopers did not cite educational and housing opportunities as reasons to stay in the UP, which may indicate a need for community leaders to address these issues. By addressing identified place-specific problems such as these, the UP may be able to retain more of its younger, unmarried residents who are needed to begin the process of revitalization.

Successful economic development also depends upon support from the local population. ${ }^{20}$ As indicated, Yoopers have a lot of faith in their community, yet they doubt the ability of their local governments to solve important problems. Community members then, not just local politicians, should be actively engaged in addressing community-level problems. For example, community groups could promote fairs, festivals, or markets to encourage tourism and generate revenue for local businesses, ultimately helping employment.

Increasing tourism and improving educational and housing opportunities are just part of a multifaceted solution to the problems faced by the UP. Such "place-based" solutions to problems should be more effective in the long run than applying universal solutions, given the wide diversity of rural American communities. More place-specific information, such as that gathered by CERA surveys, can help communities better understand the dimensions of their challenges and opportunities.

\section{Endnotes}

1. Kenneth M. Johnson, Demographic Trends in Rural and Small Town America, A Carsey Institute Report on Rural America (Durham, NH: Carsey Institute, University of New Hampshire, 2006).

2. "Yooper" refers to a resident of the Upper Peninsula of Michigan. The term was first used in the 1970s. Richard Sisson, Christian K. Zacher, and Andrew Robert Lee Cayton, The American Midwest: An Interpretive Encyclopedia (Bloomington, IN: Indiana University Press, 2007).

3. Throughout the brief, "stayers" refers to respondents who indicated that they plan to stay in the UP for the next five years, and "leavers" refers to those who plan to move away.

4. Results from the 2007 CERA survey have been described in a number of Carsey Institute reports and journal articles, including, Lawrence C. Hamilton, et al., Place Matters: Challenges and Opportunities in Four Rural Americas, A Carsey Institute Report on Rural America (Durham, NH: Carsey Institute, University of New Hampshire, 2008), http:// carseyinstitute.unh.edu/publications/Report_PlaceMatters. pdf, and Lawrence C. Hamilton and B. D. Keim,

"Regional variations in perceptions about climate change," International Journal of Climatology, 2009, http://pubpages. unh.edu/ lch/Hamilton_climate_perception.pdf.

5. Sisson, The American Midwest, 106.

6. U.S. Census Bureau, "State and County Quick Facts" (Washington D.C.: U.S. Census Bureau, 2010).

7. S. Loveridge, J. Bokemeier, and P. Kakela, "Jobs Now, Later, or ... Never? An Exploration of Resistance to Economic Change in Communities," Community Development, 38 (2) (2007):16-32.

8. From the U.S. Bureau of Economic Analysis Regional Information System; this reflects data from the Standard Industrial Classification from 1969 to 2000.

9. Kat Downs, Mary Kate Cannistra, and Nathanial Vaughn Kelso, "Interactive Map: Unemployment Rate by County," The Washington Post, http://www.washingtonpost.com/ wp-srv/special/nation/unemployment-by-county/, retrieved June 1, 2010.

10. S. Loveridge, “Jobs Now," 18.

11. Hamilton, Place Matters, 3.

12. Ibid. 
13. For further information on the challenges that young, educated, rural residents face, see Michael Corbett, Learning to Leave: The Irony of Schooling in a Coastal Community (Fernwood Publishing, 2007).

14. Sisson, The American Midwest, 106.

15. Hamilton, Place Matters, 4.

16. Chris R. Colocousis, "The State of Coos County: Local Perspective on Community and Change," Issue Brief No. 7 (Durham, NH: Carsey Institute, University of New Hampshire, 2008).

17. Hamilton, Place Matters, 5.

18. It is important to note that these unemployment rates are not seasonally adjusted and may be particularly high because they were taken during the winter when employment rates in the UP are especially low; Downs, "Interactive Map."

19. Michele Dillon and Megan Henly, "Religion, Politics, and the Environment in Rural America," Issue Brief No. 3 (Durham, NH: Carsey Institute, University of New Hampshire, 2008).

20. Loveridge, "Jobs Now," 17.

\section{ACKNOWLEDGMENTS}

The author would like to thank Larry Hamilton, Chris Colocousis, and Michael Staley for their comments and encouragement while working on this brief, as well as Kathy Ulrich.

\section{About the Author}

Jessica D. Ulrich is a doctoral student in the Department of Sociology at the University of New Hampshire and a research assistant at the Carsey Institute (jda57@cisunix.unh.edu). 


\section{ANIVERSITY}

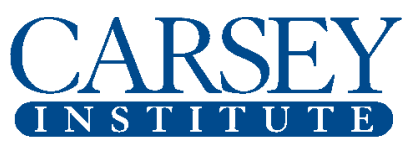

Building knowledge for families and communities

The Carsey Institute conducts policy research on vulnerable children, youth, and families and on sustainable community development. We give policy makers and practitioners timely, independent resources to effect change in their communities.

This research was supported by the Ford, W.K. Kellogg, and Charles Stewart Mott Foundations.

Huddleston Hall

73 Main Street

Durham, NH 03824

(603) $862-2821$

www.carseyinstitute.unh.edu 